\title{
Geothermal air conditioning: typical applications using deep-warm and shallow-cool reservoirs for cooling in Perth, Western Australia
}

\author{
Peter B. Whittaker ${ }^{1}$, Xiaolin Wang ${ }^{4}$, Klaus Regenauer-Lieb ${ }^{2}$, David Blair ${ }^{3}$, and Hui Tong Chua ${ }^{1, a, *}$ \\ 1 School of Mechanical and Chemical Engineering, The University of Western Australia, 35 Stirling Highway, Crawley, WA 6009, \\ Australia \\ 2 School of Earth and Environment, The University of Western Australia, 35 Stirling Highway, Crawley, WA 6009, Australia \\ 3 School of Physics, The University of Western Australia, 35 Stirling Highway, Crawley, WA 6009, Australia \\ 4 School of Engineering, The University of Tasmania, Hobart TAS 7001, Australia
}

Received 14 June 2013 / Accepted 13 November 2013 / Published online 6 February 2014

\begin{abstract}
Geothermal heat is a sustainable form of alternative energy, commonly associated with the production of electricity along tectonic plate boundaries and in volcanically active zones. Outside of these special regions however it is rare to find a geothermal gradient high enough to achieve pay back on projects for generating electricity. On the other hand regions containing sedimentary aquifers are far more common and these aquifers frequently have a sufficiently high temperature gradient to make direct use of the thermal energy attractive. Meanwhile highly permeable aquifers occurring at shallow depths are possible sources for cooling water or can be both heat sources and sinks when used in combination with heat pumps. We provide a case study for the use of thermally driven absorption chillers on the University of Western Australia campus in Perth and discuss two ongoing projects: one for the heating and cooling of the offices of the Australian Resources Research Council using a reversible heat pump and the other the climate control of the planned Australian International Gravitational Observatory.
\end{abstract}

Key words: Sustainability, HVAC, Case study, Thermo-economic analysis, Ground source.

\section{Introduction}

Sustainability becomes ever more important to engineering projects and it is forcing engineers to look at the world's natural resources in new ways. Geothermal energy has been known and exploited from ancient times in places as disparate as Roman Italy [1], pre-Columbian USA [2] and China [3]. However in modern times, since the first geothermally driven steam turbine was installed in Larderello a century ago, the production of electricity with geothermal energy has stolen much of the limelight from direct use applications - even while direct use applications now exceed 423,968 TJ per annum [4].

Every geothermal project is unique in that it has to be engineered to work within a location specific geological setting and it must address a demand that is also, to some extent, location specific. Most places in the world do not have the local geology to make electrical production practical; Perth Australia is one

\footnotetext{
a School of Environmental Science and Engineering, Taiyuan University of Technology, Taiyuan, Shanxi Province, China

*e-mail: huitong.chua@uwa.edu.au
}

such place. However Perth sits on a sedimentary basin, a vast reservoir of warm water that at moderate depths $(<1000 \mathrm{~m})$ is frequently used for heating swimming pools [5]. The local demand is for cooling and by drilling deeper into the reservoir (2000-3000 m) water can be obtained that is sufficiently hot $\left(75-95^{\circ} \mathrm{C}\right)$ to use with thermally driven absorption chillers for air conditioning. We have studied the possibility of cooling the University of Western Australia (UWA), Crawley campus, with geothermally driven absorption chillers [6] and summarize the work below in the hope that it will guide and inspire other investigators to look at the world's sedimentary aquifers when considering the sustainable resources available to them.

Shallow and or superficial aquifers offer another resource that, when correctly managed, can contribute to project sustainability. Although the temperature at shallow depths is much a function of terrestrial solar heat gain - mirroring the annual average surface temperature, the engineering and resource management have much in common with deep geothermal systems. While ground source heat pumps are common in the Northern Hemisphere [4], they are less common in Australia perhaps due 
to the need for cooling being more prevalent than the need for heating. Here we present two proposals for the clever use of heat pump systems for both heating and cooling.

\section{Case study on proposed geothermal air-conditioning at UWA}

We have performed a thermo-economic analysis on replacing a vapor compression chiller at the University of Western Australia, Crawley campus, with a geothermally heated absorption chiller [6]. The proposed absorption chiller would cover the base load cooling needs for the campus and might result in significant operational cost savings on electricity over the use of a vapor compression chiller. However the capital cost of the geothermal wells would be substantial and there is some risk of the wells not performing as expected.

\subsection{Geological setting}

The UWA Crawley campus sits on the Swan Coastal Plain and geologically within the Perth Basin [7]. The Perth Basin formed from the Permian to Early Cretaceous periods along rifts formed during the separation of Australia and Greater India [8]. The Perth Basin is up to $1300 \mathrm{~km}$ in length with the onshore component stretching more than $600 \mathrm{~km}$ along the coast, from north of Geraldton to South of Bunbury and is as much as $15 \mathrm{~km}$ thick.

The source for geothermal waters targeted in the proposed UWA project is the Yarragadee formation, made up of thick, fluvial sandstone. The nearest deep well to the UWA Crawley campus is Cockburn 1; a dry hole oil well drilled in 1967 and situated roughly $18.5 \mathrm{~km}$ to the south. Well logs from Cockburn 1 show at a depth of $3 \mathrm{~km}$ that the Yarragadee has a temperature of $95^{\circ} \mathrm{C}$ and a permeability of 0.6-0.7 Darcy. Given an average surface temperature of $20^{\circ} \mathrm{C}$, this translates to a geothermal gradient of about $25{ }^{\circ} \mathrm{C} / \mathrm{km}$, fairly typical for sedimentary aquifers.

\subsection{Chiller specification}

Three years of campus cooling data (2008-2010) from the UWA central plant show that while the peak load in the summer can be as high as $15 \mathrm{MW}$, the base load is somewhere between $1 \mathrm{MW}$ and $3 \mathrm{MW}$. Moreover, the actual daytime load on the vapor compression chillers even during peak periods is only 8.5 MW due to the use of a large chilled water storage tank capable of providing $24 \mathrm{MWh}$ of cooling during the day and recharged by the chillers during the night, to take advantage of off peak electricity rates. This investigation focuses on using two thermally driven lithium-bromide absorption chillers, cascaded to give $2 \mathrm{MW}$ of cooling capacity to cover the base load demand. Water could be pumped up from the Yarragadee at $\sim 95^{\circ} \mathrm{C}$ through a production well, passed through the two chillers in series and then returned to the aquifer at a shallower depth with a temperature of $\sim 70{ }^{\circ} \mathrm{C}$ through an injection well.

\subsection{Economic analysis}

\subsubsection{Capital cost}

The capital costs of the proposed project include the two absorption chillers, pumps, piping and fittings to connect the wells to the chillers and the chillers to the existing campus cooling network and the cost of the wells themselves. Most of these costs can be found in a straight forward manner, by contacting manufactures. However the largest cost by far comes from drilling and completion of the wells and this cost can, at best, only be estimated. The estimate was made by using the Wellcost Lite model [9] to compare the price of geothermal wells to the cost of oil wells in 2003 US dollars. The cost has been updated using the US PPI for Oil and Gas Drilling [10] to 2011 US dollars and converted to Australia dollars at contemporary exchange rates. A caveat to this approach is that the actual cost of drilling appears to be higher in Australia than in the US, however hard data on Australian drilling costs was unavailable.

Based on the Cockburn 1 well data, the production well must reach to roughly $3 \mathrm{~km}$ depth and the injection well will need to be about $2 \mathrm{~km}$ deep.

\subsubsection{Operating cost}

Operational cost savings are calculated by comparing electrical use data and water consumption data collected from 2008-2010 against the estimated loads that would exist had the proposed system been in place during the same period, completely covering all cooling loads up to $2 \mathrm{MW}$. For periods of demand greater than $2 \mathrm{MW}$ it is assumed that the existing vapor compression chillers would be used to take up the excess load.

The electricity consumed by the chillers was found from manufacturers catalogues and is about $1 \%$ of chiller capacity. Pumping power for the geothermal wells was found using the model of Ungemach and Antics [11] for reservoir drawdown and conventional fluid flow correlations for the pressure losses due to flow in the wells, pipes and heat exchangers.

Two different methods of heat rejection for the absorption chillers were considered, one in which the existing cooling towers were used (no change to electricity use, water use or sewage) and another in which the heat was rejected to the superficial aquifer via a set of production and injection wells spaced at opposite ends of the campus (an increase in electricity used for pumping but no water or sewage costs).

\subsubsection{Government funding opportunities}

Several government funding opportunities existed for the project and were taken into account in the financial analysis. The Australian Federal Government offered up to \$7 million for a "proof of concept" through the Federal Geothermal Drilling Program [12], on a 1:1 funds matching basis to be used to offset drilling costs. The Western Australian State Government offered a further \$5.4 million through the Low Emissions Energy Development fund [13], on a 1:3 funds matching basis. 
Table 1. Key financial and pumping model assumptions (adapted from Wang et al. [6]).

\section{Project lifetime}

Cost of capital (nominal)

Inflation rate based on current Australia CPI

Corporate tax rate based on current Australia taxation scheme

Depreciation

Federal government funding for proof of concept

State government funding implemented over 5 years' time

Projected electricity price increase

Carbon tax based on current Australian taxation office

Carbon price increase

Make-up water price increase

Drainage water price increase

Yarragadee aquifer permeability

Temperature gradient

Geothermal well screen height

Injection pump efficiency

Submersible pump efficiency for the production well

Distance between production and injection wells

Well diameter
Key financial assumptions

$20-30$ years

$8 \%$

$2.7 \%$

$30 \%$

Straight line, no residual value

$50 \%$ of well costs capped at $\$ 7$ Million AUD, up front ${ }^{12}$.

$\$ 1$ matches every $\$ 3$ project expenditure capped at $\$ 5.4 \mathrm{M}^{13}$. $2.7 \%$

$\$ 23$ / tonne $\mathrm{CO}_{2}$

$4 \%$ per year

$16 \%$ in $201214 \%$ in $201310 \%$ in 2014 and 5\% onwards

$1.8 \%$ per year

Pumping model assumptions

$0.1-0.7$ Darcy

$25{ }^{\circ} \mathrm{C}$ per $\mathrm{km}$

$200 \mathrm{~m}$

$80 \%$

$65 \%$

$800 \mathrm{~m}$

$250 \mathrm{~mm}$

Table 2. Thermo-economic results of the proposed UWA cascaded absorption chiller scheme with a Yarragadee permeability of 0.3 Darcy (adapted from Wang et al. [6]).

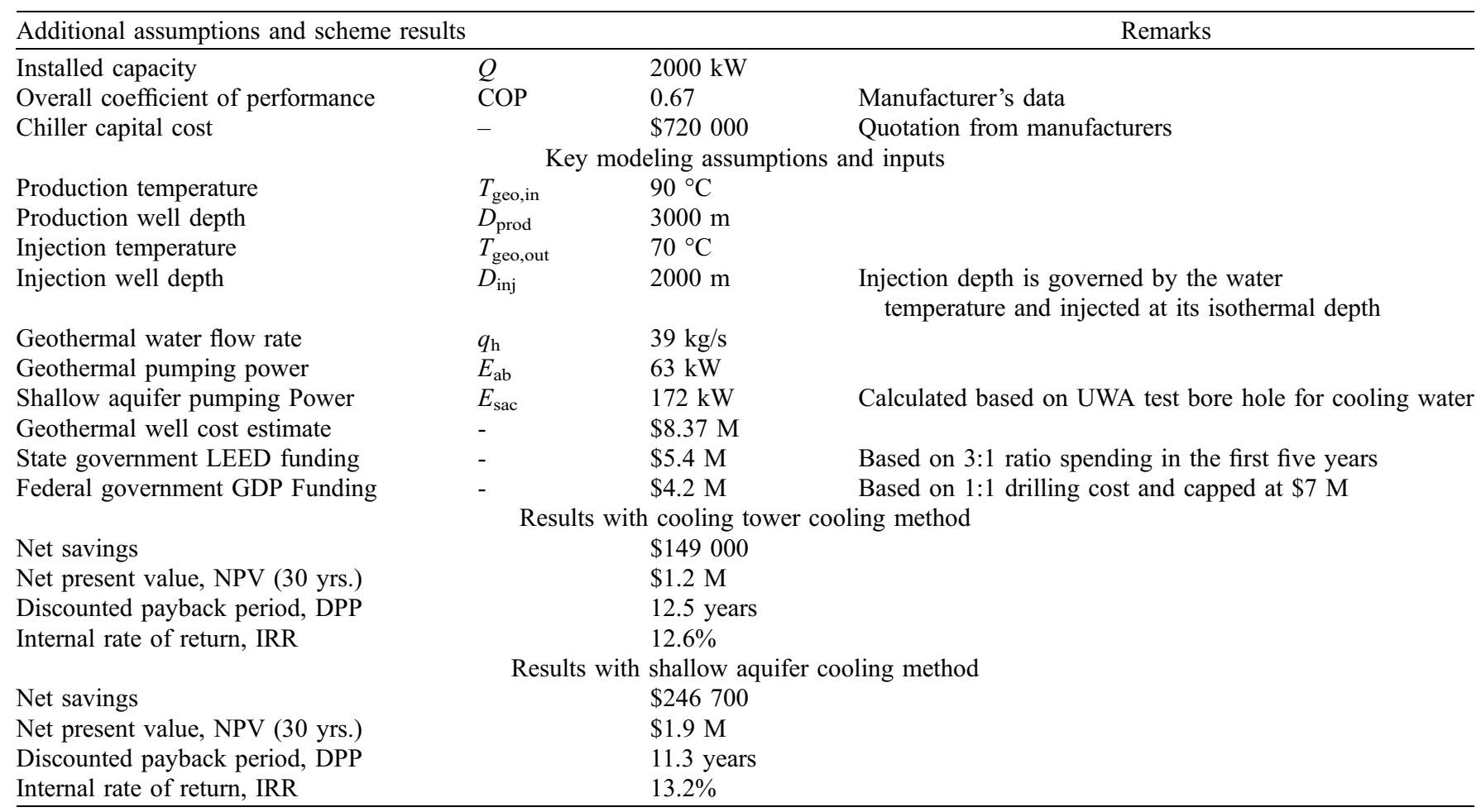

\subsubsection{The effect of carbon taxation and trading}

The effect of carbon taxation and trading on electricity pricing was entered into the model based on a variety of scenarios with likely electricity rate increase as estimated by the Federal Treasury [14].

\subsection{Results and discussion of the study}

Key assumptions are listed in the Table 1 and key results are given in Table 2. With Government funding and a middle of the road carbon tax scheme (Garnaut-10 scenario [14]), the net present value based on a 20 year project life is $\$ 1.2$ million 

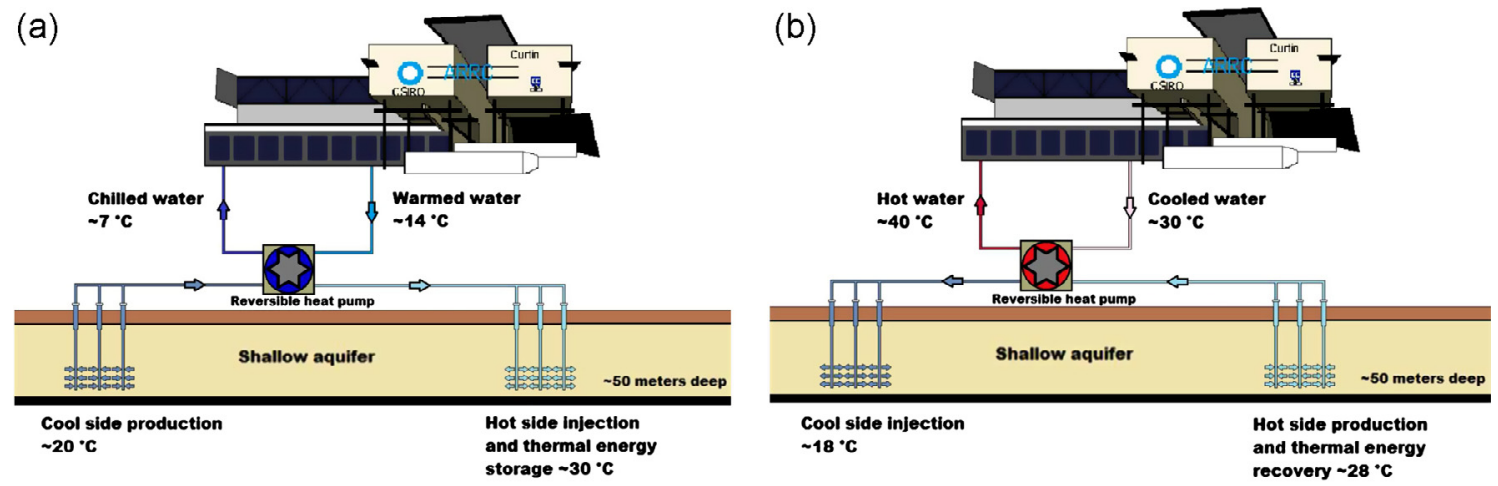

Figure 1. A ground coupled reversible heat pump could be used for space heating and cooling of the ARRC building. By being able to produce from and reinject to all wells, it is possible to isolate and reuse the heat rejected in summer (a) during winter space heating (b). Not shown is a chilled water storage tank that would be charged during the night in the summer and used for supplementary cooling during the day.

with heat rejected to the cooling towers and $\$ 1.9$ million with heat rejected to the superficial aquifer. The payback period is $11-13$ years.

Based on the analysis, this project is viable. The payback period is reasonable given that the proposed project would be novel in several respects - the first deep geothermal project in Western Australia and the first deep geothermal project in the world (to the best of the authors knowledge) to be done purely for air conditioning.

\section{Proposal for using a reversible heat pump at the ARRC building}

The Australian Resources Research Centre (ARRC) building sits in a technology park in the south Perth suburb of Kensington. It is a center of collaboration between the Commonwealth Scientific and Industrial Research Organization (CSIRO), the Western Australia State Government, Curtin University and various petroleum and mining industrial interests. In addition to the researchers, support staff, labs and related office equipment the building also houses one of Western Australia's iVEC supercomputing hubs, which contributes substantially to the base load cooling demand. Because of the many entities connected to work done in the ARRC building, the site has the potential to be one of the most visible demonstrations of sustainable, direct use geothermal technology.

Currently the building is cooled by a number of vapor compression chillers, all of which but one, use air cooled condensers with an overnight base load of about $200 \mathrm{kWth}$ (mostly from the super computer) and summer time peak load of about 2 MWth. Heating is by natural gas. At this time heating load data is incomplete but in Perth the need for space heating is generally equal to or less than the need for cooling.

We are investigating a shallow geothermal solution to the heating and cooling of the ARRC building - an open loop reversible heat pump system with wells to a depth of less than $80 \mathrm{~m}$ below the surface. Indications are that a shallow confined aquifer in this region (the Mullaloo) is highly permeable and should easily sustain the flow rates necessary for a $\sim 500 \mathrm{kWth}$ heat pump system. The open loop system with both production and injection wells would result in no net extraction within this aquifer which is important; shallow ground water is in high demand in the Perth metropolitan area for both drinking water and garden wells.

Having well doublets (paired production and injection wells) would allow for underground thermal energy storage (UTES) [15]. With one well of the doublet pair serving as the cold well from which water would be extracted during the summer and the other well becoming the hot well to which warmed water would be injected. By having pumps in both wells, in the winter the direction of flow could be reversed with the hot well becoming the producer, returning some of the heat that had been rejected to it. This arrangement shown in Figure 1, could not only increase the overall system coefficient of performance (COP) but also reduce the dangers of thermal feedback between the hot and cold wells - together with an understanding of the local hydraulic gradient and proper well spacing feedback might be avoided all together $[15,16]$.

By incorporating a chilled water storage tank, during the summer the heat pump system could run over night, charging the storage tank and taking advantage of off peak electric power rates and during the day the storage tank would be used to augment the capacity of the heat pump. While it is impractical to size such a system to cover peak loads, as planned the system might reduce the need to run a vapor compression chiller to only the hottest hours of the day during the summer and similarly a gas fired boiler could be used primarily for domestic hot water and used for space heating only during peak periods during the winter.

\section{Proposal for using shallow aquifer cooling water at AIGO}

The Australian International Gravitational Observatory (AIGO) will be built $70 \mathrm{~km}$ north of Perth, adjacent to the current Gingin observatory and Gravity Discovery Centre, inside of $50 \mathrm{~km}^{2}$ of state forest (Figure 2). AIGO will be part of an international group of ultra-sensitive gravitational wave detectors and the only such detector located in the Southern Hemisphere. The detector must be sensitive enough to perceive changes in length on the order of $10^{-19} \mathrm{~m}[17]$ and this poses a unique challenge to climate control in the AIGO - the 


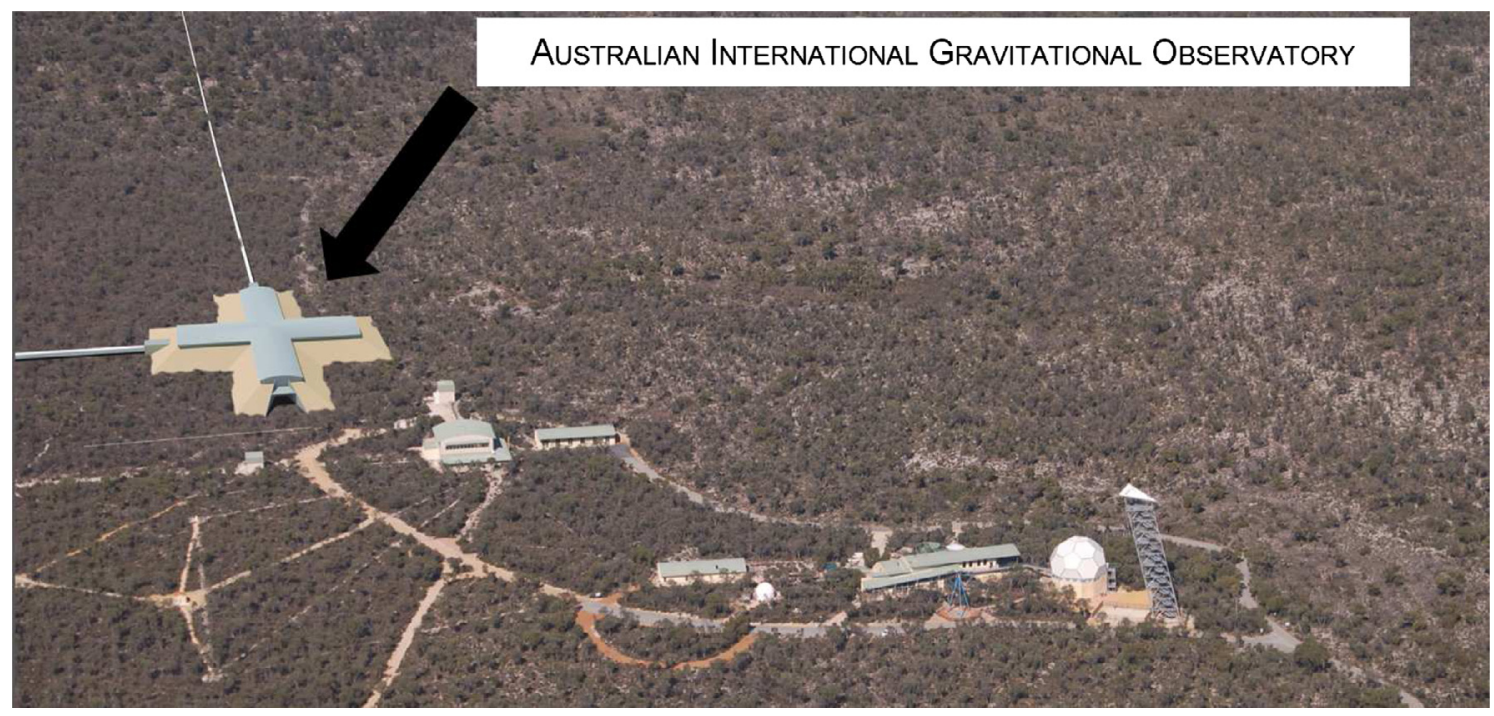

Figure 2. Conceptual drawing of the Australian International Gravitational Observatory (adapted from concept model by Simon Anderson). The, to be constructed, observatory is the cross shaped building in the upper left. On the lower right is the Gravity Discovery Centre and Gingin Observatory while closer to the proposed AIGO building is an already existing but much smaller interferometer.

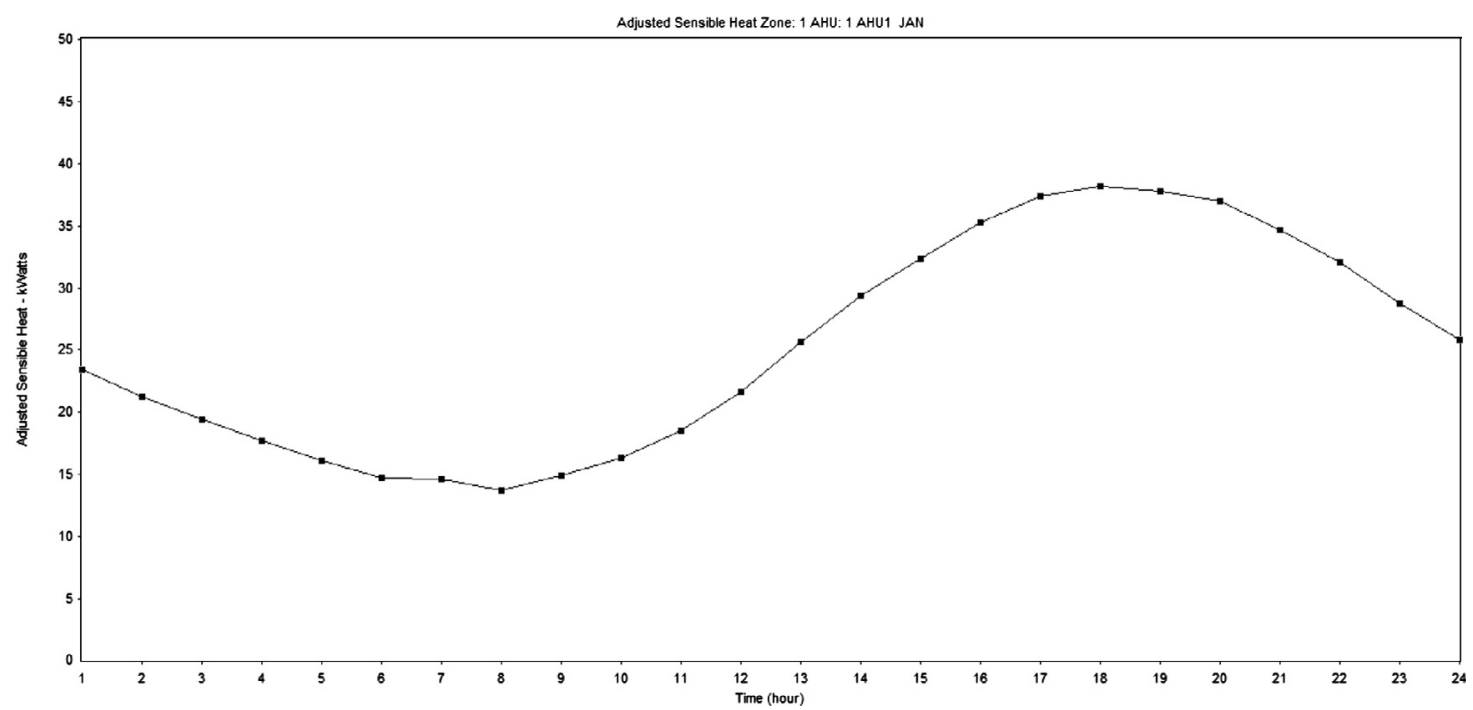

Figure 3. Predicted peak day cooling load for the AIGO building during the month of January. Peak cooling load is expected to occur during January and peak heating load during July of each year. With the indoor temperature fixed between $22{ }^{\circ} \mathrm{C}$ and $23{ }^{\circ} \mathrm{C}$ the model, built in the program CAMEL by AGADS-EGS, predicts balanced heating and cooling loads with peak values for each of around $40 \mathrm{kWth}$.

instruments must be kept isolated from vibration and the temperature must be kept essentially constant to avoid thermal strain.

The main AIGO building will be the corner of a large interferometer and house the lasers and beam splitter. The building will be in the shape of a cross with walls $10 \mathrm{~m}$ high and the internal area will be roughly $3400 \mathrm{~m}^{2}$. To shield the building from wind induced vibration, sand berms will be piled up against the walls of the AIGO to a height of $8 \mathrm{~m}$. During day to day operation there will be only minimal internal lighting and the AIGO will be only intermittently occupied by a small group of researchers. The roof of the building will be heavily insulated and the sand berms will provide both shading to the walls and additional thermal mass that should attenuate fluctuations in the temperature of the building.
For the climate control system of the AIGO we have proposed that base load be covered by a ground coupled vapor compression chiller and separate ground coupled heat pump with both the cooling and heating system using vertical wells. The choice of a separate chiller and heat pump rather than a reverse cycle heat pump comes from a desire to avoid transient effects on the temperature of the air delivered to the AIGO and the ability to align routine maintenance tasks on the heating and cooling systems with the seasons when those respective systems will not be in use. Vertical wells are favored over a horizontal "slinky tube" setup in this case because the temperature at depth should be far more constant $\left(\sim 20^{\circ} \mathrm{C}\right)$ over the course of a year than it would be near surface, which should translate to more consistent system performance. The chiller and heat pump will deliver cooling and heating to 
insulated water storage tanks which will in turn be coupled to the air handling unit. Using the water storage tanks to provide cooling and heating rather than the chiller and heat pump directly should allow for more precise temperature modulation and allow the system to take advantage of off peak electrical rates. An air coupled chiller and air coupled heat pump would be used to handle peak loads thereby avoiding oversizing the ground coupled well field.

We have modeled the heating and cooling loads of the proposed AIGO building (Figure 3) and found that keeping the indoor air temperature at a constant value between $22{ }^{\circ} \mathrm{C}$ and $23{ }^{\circ} \mathrm{C}$ will allow for a balanced heating and cooling load on the ground coupled well field. A balanced load should in turn contribute greatly to project sustainability allowing the temperature of the well field to remain nearly constant for years into the future. Because the AIGO roof is well insulated, because there are no windows and because the building is partially buried we've found the peak heating and cooling loads to be in the neighborhood of $40 \mathrm{~kW}$ which is quite small for such a large building.

Future work will focus on designing the ducting such that the air temperature at all points in the building will be invariant with respect to space as well as time. The AIGO will be maintained at positive pressure and at air distribution points there will be HEPA filters in order for the entire building to meet the standards of a class 10000 clean room. Additionally laminar flow diffusers will be used to further minimize vibrations induced by the incoming air.

\section{Conclusions}

We hope that this paper will serve as an inspiration to engineers looking for sustainable ways to cool and heat buildings. A case study is summarized, for a proposed geothermally driven air conditioning system that can be used to bench mark other, similar projects. Some ideas for an open loop, ground coupled, reversible heat pump system are discussed in the context of heating and cooling an office building. Finally a high performance climate control system for an international scientific observatory is described, in which the performance and reliability are substantially enhanced by using ground water as alternately a heat sink in summer and a heat source in winter.

\section{References}

1. Carlino S, Somma R, Troise C, De Natale G. 2012. The geothermal exploration of campanian volcanoes: historical review and future development. Renew. Sust. Energ. Rev., 16, 1004-1030.

2. U.S. Dept. of Energy. A History of Geothermal Energy in the United States, http://www1.eere.energy.gov/geothermal/ history.html on 26th Aug. 2012.
3. Kearey P, HongBing W. 1993. Geothermal fields of China. Volcanol. Geoth. Res., 56, 415-428.

4. Lund JW, Freeston DH, Boyd TL. 2011. Direct utilization of geothermal energy 2010 worldwide review. Geothermics., 40, 159-180.

5. Oldmeadow E, Marinova D. 2011. Into geothermal solutions: the sustainability case for Challenge Stadium in Perth, Western Australia. Environ. Prog. Sustain. Energ., 30, 476-485.

6. Wang X, Bierwirth A, Christ A, Whittaker P, Regenaur-Lieb K, Chua HT. 2013. Application of geothermal absorption airconditioning system: a case study. App. Therm. Eng., 50, 7180.

7. Raine MJ, Smith KG. 1972. Bibliography of the Perth Basin. In: Geology and Geophysics. Canberra: Bureau of Mineral Resources.

8. Geoscience Australia. http://www.ga.gov.au/energy/province-sedimentary-basin-geology/petroleum/offhshore-southwest-australia/ perth-basin.html (on 26th Aug. 2012).

9. Augustine C, Tester T, Anderson B. 2006. A comparison of geothermal with oil and gas well drilling costs. Proceedings of the 21st workshop on Geothermal Reservoir Engineering, Stanford University, California.

10. U.S. Bureau of Labor Statistics Producer Price Index. http://www.bls.gov/ppi/.

11. Ungemach P, Antics M. 2009. Sustainable geothermal reservoir management practice, International Course and EGEC Business Seminar on Organization of a Successful Development of a Geothermal Project. International Geothermal Days, Conference \& Summer School, Slovakia.

12. Australian Department of Resources. 2008. Geothermal Drilling Program Fact Sheet. Australian Department of Resources, Energy and Tourism (DRET), Australian Government, http://www.agea.org.au/dyn/media/news/attachment/47.

13. Western Australia Department of Environment and Conservation (DEC). 2010. Low Emissions Energy Development Fund: Application Guidelines. Western Australia Department of Environment and Conservation (DEC), Government of Western Australia, http://www.finance.wa.gov.au/cms/content.aspx?id=14590.

14. McLennan Magasanik Associates. 2008. Impacts of the Carbon Pollution Reductions Scheme on Australia's Electricity Markets, a Report to Federal Treasury of Australia. Melbourne: Federal Treasury.

15. Banks D. 2009. Thermogeological assessment of open-loop well-doublet schemes: a review and synthesis of analytical approaches. Hydrogeol. J., 17, 1149-1155.

16. Banks D. 2009. An introduction to "thermogeology" and the exploitation of ground source heat. Q. J. Eng. Geol. Hydroge., 42, 283-293.

17. AIGO Proposal. 2011. LIGO-AUSTRALIA - on the crest of the wave. LIGO Proposal by the University of Western Australia on behalf of the member universities of the Australian Consortium for Interferometric Gravitational Astronomy (ACIGA), Western Australia, http://www.anu.edu/Physics/ACIGA/LIGO-Australia_ Proposal_LR.pdf.

Cite this article as: Whittaker PB, Wang X, Regenauer-Lieb K, Blair D \& Tong Chua H: Geothermal air conditioning: typical applications using deep-warm and shallow-cool reservoirs for cooling in Perth, Western Australia. Int. J. Simul. Multisci. Des. Optim., 2014, 5, A10. 